\title{
The key technologies research of Guizhou minority cultural heritage digital protection
}

\author{
Zhou Guixian ${ }^{1, a^{*},}$ Xu Hongfeng ${ }^{2, b}$ \\ ${ }^{1}$ Information Institute GuiZhou College of Financial and Economic, GuiYang 550004, China \\ ${ }^{2}$ Information Institute Guizhou Normal University, GuiYang 550004, China GuiYang 550004, China \\ a120362538@qq.com, b3138918343@qq.com
}

Keywords: Guizhou minority; digital protection

Abstract. Guizhou ethnic history and culture as the excellent cultural heritage is a precious. Research on key technology of digital cultural heritage protection, proposed in view of the cultural heritage of minorities in guizhou new method of digital protection way.

\section{Introduction}

Today's business environment is more competitive than ever. Material and non-material cultural heritage represents our ancestors have created splendid culture. With the development of social economy, the protection of cultural heritage has been more and more attention by governments around the world and academics. With the development of multimedia and graphics image processing technology, especially the end of the twentieth century the rise of virtual reality technology and the rapid development of network, cultural heritage protection has a new way - high precision high lifelike digital heritage protection technology. Cultural heritage digital protection requirements have been widespread cognition. In the early $1970 \mathrm{~s}$, people began to use photography camera technology such as cultural relics information, but these data is difficult to save for a long time, the aging, such as video image reproduction will produce distortion, etc. High precision high lifelike digital heritage protection technology using artificial intelligence, virtual reality, advanced information technology such as multimedia, broadband network and database, development of new practical support system based on computer and network environment or means, overcome difficulties, to serve the sustainable development of the cultural heritage. By means of cultural heritage related text, images, sound, video and $3 \mathrm{~d}$ data information digital preservation, organization, storage and retrieval system, and further set up digital cultural heritage museum, the exhibition hall, for the protection of cultural heritage, development and utilization of services. The development of information technology, especially digital photography, $3 \mathrm{~d}$ information acquisition, virtual reality, multimedia and broadband network technology, the development of the research and application for the material and non-material cultural heritage digital research and conservation development provides a solid technical foundation.

The digital information technology research in the field of large material cultural heritage has entered a benign orbit, but in the intangible cultural heritage is still in its infancy in the areas of application. How to use digital technology rich intangible cultural heritage protection, this is the scientific workers and protection of non-material cultural heritage experts facing the new project. For intangible cultural heritage, we should not only protect and save them, but also by the new method and means to reinterpret them, giving them new meaning, so as to make them is closely related to our real life forever.

\section{DIGITAL PROTECTION NECESSITY AND URGENCY}

China is a unified multi-ethnic country, 56 ethnic groups in the long-term production and life practice, created colorful ethnic culture, especially in various forms, characteristic, connotation rich tradition of folk literature, music, traditional dances, traditional arts, traditional arts, traditional medicine and folk intangible cultural heritage. Protect and make good use of the intangible cultural heritage, is to maintain an important foundation for the survival and development of all ethnic groups, 
to promote national unity, maintaining national unity and maintain cultural diversity of the Chinese nation, build the common spiritual home for the Chinese nation, to promote comprehensive, balanced and sustainable development of economic society in national regions, it is of great significance. But in the overwhelming trend of globalization and the process of social modernization in our country, especially with the passage of modernization and urbanization, the population of large flow, the popularity of radio and television bring the improvement of national informatization, traditional production way of life is undergoing unprecedented changes, traditional architecture, traditional production articles for daily use, such as integrated accelerated. In the development of society, in the progress of science and technology, backward production tools, life utensils replaced by advanced production tools, life utensils, rich ethnic and cultural diversity activities gradually being assimilated into modern civilization, it is historically inevitable. However, the development of society, science and technology progress is a historical process, are implemented on the basis of a certain, is unlikely to occur out of thin air. Therefore, keep some representative of the production, life appliance, activities, products, as well as the manufacture, use, production, life appliance, activity supplies of traditional crafts, is culture, is the witness of history.

On May 20, 2006, the state council of the People's Republic of China announced the first batch of state-level non-material cultural heritage list in 518, the ethnic minorities accounted for a third of the project. But with the speeding up of industrialization and urbanization, the environment to the survival of folk traditional culture change sharply, a large number of natural or man-made damage to the resource. Each nation in the history of relying on oral inheritance of various skills, and behavior custom, etiquette, such as cultural heritage danger, ethnic architecture, traditional crafts, clothing accessories, music, dance, and myths and legends, folk songs, folk artists because of not enough and lack of protection, are dying off, especially because of the lack of records means lost and forgotten by the people, because of the lack of display media, due to lack of innovation development but not the continuation and development. Using text, audio, video, digital multimedia and other modern means of science and technology of rare or endangered and identity of the minority cultural heritage of historical value, system and comprehensive records, files and databases is the Chinese national folk culture protection project of one of the main implementation content. Therefore, the use of digital information technology means for the minority cultural heritage protection, it is very important and very necessary.

\section{THE KEY TECHNOLOGIES OF CULTURAL HERITAGE PROTECTION}

\section{Digital collection technology}

Physical exhibits of guizhou minorities and cultural elements are collected, using digital equipment with text, video, images, audio and other media for recording, digital minority cultural elements. Purpose is to establish in the computer related digital model, for guizhou minority cultural heritage protection and restoration of information sharing, and archaeological study, visit and provide the accurate digital material such as development and utilization.

For planar objects such as the ancient books, calligraphy, paintings, etc., first with high precision digital camera or flat scanner to digital related to cultural relics, generate $2 \mathrm{~d}$ images, and image processing technique was applied to the image processing and analysis.

For three-dimensional culture works, such as the miao diaojiao building, which is based on three-dimensional color scanner based on multi-angle photographs to get the data in a way that the data collection, record, and by adopting the technology of reverse engineering, data processing, correction, and building of surface modeling and entity of cultural relics of the three dimensional digital information.

For music and dance, folk memories, such as ethnic minority culture, through the digital acquisition equipment such as audio, video acquisition card, national culture digital acquisition. 
Minority cultural works digital representation and replication technology

Based on reverse engineering and rapid prototyping technology can recover guizhou national minority material cultural heritage, such as dong, wind and rain bridge, anshun to play face masks and narrow copy as souvenirs for later viewing, so as to promote the development of material types of ethnic culture protection, promote the protection of cultural relics and the development of tourism in guizhou. Reverse engineering (RE) in view of the existing $3 \mathrm{~d}$ material physical, measured by digital measurement structure necessary data information on free curved surface, after processing by the 3D CAD modeling, and generate STL file, and then through rapid prototyping machine (such as LOM, FDM) rapid model products. It involves the key techniques include: 3D solid geometry data rapid acquisition, large dense discrete data processing and the three-dimensional solid model reconstruction. Its working process is: the physical prototype of a data acquisition, data processing $\mathrm{CAD}$ geometric model a STL file.

Multimedia data encoding and retrieval technology

Digital museum experience processing images, audio, video, and model of digital multimedia signal. Digital multimedia data volume is amazing. If considering the ethnic culture to deal with images, audio, video, digital museum, model number and the corresponding client request, the need of storage and transmission of geometric data quantity will increase. Even for the modern mass storage devices and high speed Internet, for such a mass of data, if not handled, also can't afford.

After collecting and organizing of the minority cultural elements, characteristics analysis of guizhou ethnic minorities culture elements, library, set of guizhou minority ethnic cultural characteristics of ethnic cultural heritage to cultural characteristics, from the following several characteristics index of ethnic culture to represent characteristics of element analysis:

Cultural characteristics: Historical characteristic, Regional characteristic, National characteristics, Visual characteristics, Process characteristics.

Refine each feature definition, quantitative indicators, respectively, and compare the various elements, for each paper, cultural characteristics of digital works so as to extract the characteristics of guizhou ethnic minorities culture elements.

Non-material cultural heritage digital induction technology

Digital inductive technology refers to the characteristics of guizhou ethnic minorities culture elements, which can identify, and save them in a computer, to create original features database. Such as the embroidery painting and calligraphy works to extract the stored pattern characteristics of $2 \mathrm{~d}$ pattern of style and color collocation, guizhou folk painting and calligraphy, fine arts, such as MiaoXiu (built leishan MiaoXiu, huaxi MiaoXiu, jian river MiaoXiu) and aquarium water book, horsetail embroidery, they have a large number of patterns and high protection value, and the colour is tie-in with very strong national characteristics and cultural background. Can use to create pattern database to these precious intangible cultural heritage in guizhou are saved, and can be controlled by computer to implement the design style of writing. Using audio feature analysis method, constructs the ethnic music tune signature database, etc. The use of artificial intelligence and neural network technology to deal with the extracted data, establishing database of cultural inheritance.

\section{PROTECTION DIGITAL PLATFORM DESIGN}

Guizhou minority cultural heritage protection digital platform design can be divided into general design and detailed design, general design of the main task is to put the demand analysis of DFD is converted into a data structure, software structure is a software platform for the development of a detailed design steps, is a summary of design refinement, each module detailed design algorithm, the local structure, etc.

This platform was designed and developed in pure Java2, meaning all the components were implemented using the Java programming language and the software components used are Java compatible. The design architecture is multi-tiered as explained in the previous chapter and hence it is extensible. Since the design is modular, most of the components on the server can be modified and 
changed seamlessly as long as the components maintain their core API (Application Programming Interface). Through this interface any changes in the server objects do not concern the end user. In addition, the client can also change the look and feel or navigation without having to worry about the change to the interfaces or logic.

\section{SUMMARY}

In order to speed up the progress of the research on cultural heritage of minorities in guizhou, the better to protect the local characteristics of ethnic minorities in guizhou precious cultural heritage, we in view of the current cultural heritage of minorities in guizhou conflict between rational development and utilization and effective protection, and put forward a digital technology in guizhou minority cultural heritage protection research and application development solutions, through digital equipment of guizhou ethnic minorities culture to explore, information acquisition and storage, set up a digital technology based integrated digital minority cultural repository; The realization of digital display of minority cultures, ornamental, spread; Was carried out on the material culture of minorities in guizhou characteristic element digital inductive, establishing database of guizhou ethnic minorities culture symbol library and material, in ensure that digital records of the accuracy and authenticity of minority culture and art ontology at the same time, promote the minority cultural heritage of the inheritance, development and development. At the same time, through project research is helpful to cultivating guizhou minority cultural heritage digital protection and development technical team. Through the key technology research and application development, cultivate our province guizhou cultural heritage protection and development and application in digital professional team; Through management training and technical training, develop our digital cultural heritage protection and development of applied talents.

\section{Fund Project Sponsors}

This paper is supported by the Doctor Research Foundation, Soft science research project in guizhou province R number :[2012] LKC2016.

\section{References}

[1] KI M,,KYUNG-HOI.Local Identity and Sport:Study of Sym-bolismof Expression in Saja-Chum. . 2004

[2] Peter Howard,David Pinder.Cultural heritage and SUStainability in the coastal zone:experiences in south westEngland. Journal of Cultural Heritage . 2003

[3]Brian Stoddart."Orientalism,Golf and the Modern Age:Joe Kirkwood in Asia". Sporting Traditions:Journal of the Australian Society for Sports History . 1999

[4] Helen Watkins,David Herbert.Cultural policy and place promotion:Swansea and Dylan Thomas. Geoforum . 2003

[5]Patrick West."Worlds apart:a comparison between physical activities among youth in Glasgow,Scotland and Dunedin,New Zealand". social Science \& Medicine . 2002

[6]SANADA,Hisashi."Transformation of 'Soma-Nomaoi(Wild-horse Chasing)' in Fukushima,Japan". Local Identity and Sport . 2004 